\title{
Psicanálise, saber e conhecimento
}

\author{
Ana Cabral Rodrigues ${ }^{\star}$, Carlos Alberto Ribeiro Costa ${ }^{\star \star}$, Marcos Eichler \\ de Almeida Silva ${ }^{\star \star \star}$ e Edson Pereira da Silva ${ }^{\star \star \star \star ~}$ \\ Resumo
}

Em fins do século XIX ocorre, no plano da construção de conhecimentos, uma revolução: Freud, Marx e Nietzsche equivocam a certeza. Posteriormente, Göedel demonstra que, num sistema lógico, existe a possibilidade de contradição, um furo. A partir disto, este trabalho estuda as condições de produção do conhecimento em psicanálise, propondo uma dupla visada: lançar um olhar epistemológico sobre a psicanálise e pensar uma epistemologia a partir do que aquela possui de mais próprio e radical o Inconsciente. Acreditamos que o estudo desta relação é uma importante questão epistemológica, relevante para a compreensão da atividade científica como um todo.

Palavras-chave: Psicanálise. Epistemologia.Conhecimento.

\section{Psychoanalysis, acquaintance and knowledge}

\begin{abstract}
Towards the end of 19th century, a revolution takes place in the field of knowledge production: Freud, Marx and Nietzsche introduce the idea of a

^ Psicóloga (Universidade Federal Fluminense), mestranda no Programa de Pós-graduação em Estudos da subjetividade (Universidade Federal Fluminense), membro do Grupo de Estudos e Pesquisas em Ensino e Epistemologia (GEPEE). Rua Tiradentes 108/503A, Ingá, Niterói, RJ. CEP: 24.210-510.

E-mail: anacro@netmail.com.br

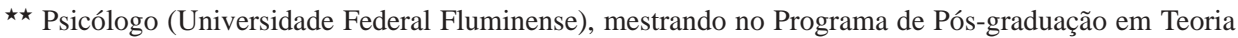
Psicanalítica (Universidade Federal do Rio de Janeiro), bolsista CNPq, estudante do curso de especialização em Psicanálise e Laço Social (Universidade Federal Fluminense), membro do Grupo de Estudos e Pesquisas em Ensino e Epistemologia (GEPEE). Rua Dr. Celestino 42, apto 606, Centro, Niterói, RJ. CEP: 24.020091.

E-mail: carlos.a.costa@email.com

$\star \star \star$ Psicólogo (Universidade Federal Fluminense), mestrando no Programa de Pós-graduação em Teoria Psicanalítica (Universidade Federal do Rio de Janeiro), bolsista CNPq, estudante do curso de especialização em Psicanálise e Laço Social (Universidade Federal Fluminense), membro do Grupo de Estudos e Pesquisas em Ensino e Epistemologia (GEPEE). Rua Miguel Couto, 315/301, Icaraí, Niterói, RJ. CEP: 24.230-240.

E-mail: marcoseichler@openlink.com.br

$\star \star \star \star$ Professor Adjunto do Instituto de Biologia, Pós-doutorando em genética pela Universidade de WalesSwansea, Doutor em Genética pela Universidade de Wales-Swansea, Chefe do Laboratório de Genética Marinha da UFF, onde trabalha com genética de populações utilizando métodos moleculares e responsável pelo Grupo de Estudos e Pesquisas em Ensino e Epistemologia (GEPEE). Universidade Federal Fluminense, Outeiro São João Batista, s/nº, Valonguinho, Niterói, - RJ, CEP: 24.001-970.

E-mail: gbmedson@vm.uff.br
\end{abstract}


not totally guaranteed certainty. Afterwards, Gödel demonstrates the possibility of contradiction in a given logical system. Parting from these premises, this assay studies the knowledge production conditions in psychoanalysis and proposes a two way analysis: thinking psychoanalysis from an epistemological point of view, as well as thinking the contribution of psychoanalysis theory of Inconscient to an epistemology. We believe that the study of this relation is an important epistemological question, relevant to the comprehension of scientific activity as a whole.

Keywords: Psychoanalysis. Epistemology. Knowledge

\section{INTRODUÇÃo}

Utilizando noções correntes na epistemologia contemporânea - sujeito, objeto, fenômeno, entre outros - este trabalho tem como objetivo entender as condições de produção de conhecimento em psicanálise. Para tanto, buscamos estudar as condições de produção do conhecimento científico no seu modelo tradicional cartesiano e a especificidade da experiência analítica. Nosso intuito, no entanto, não é demonstrar que a psicanálise pode ou não ser reconhecida como uma ciência a partir dos critérios de cientificidade tradicionalmente estabelecidos, mas sim o de propor uma dupla visada: lançar um olhar epistemológico sobre a psicanálise e pensar uma epistemologia a partir do que a psicanálise possui de mais próprio e radical - a noção de Inconsciente.

\section{A CIÊNCIA MODERNA}

Há alguns séculos, mais precisamente no ano de 1641, René Descartes introduz aquilo que viria a ser conhecido como o cogito cartesiano (DESCARTES, 1641/2000). Incapaz de estabelecer uma garantia de equivalência entre a "coisa" e o "pensamento da coisa", Descartes, através do "método da dúvida", funda no pensamento, e no ser que pensa, sua certeza: "penso, logo existo". O cogito marca a emergência de uma nova forma de pensar o mundo e, a partir da disjunção entre o pensamento (res cogitans) e a extensão (res extensa), ergue-se um abismo entre o "sujeito" e o "mundo", que passam então a ser compreendidos como instâncias separadas. Sob a égide desta disjunção, dá-se um movimento de "esvaziamento" de todo conhecimento do mundo (real) que seja erigido sobre contingên-cias e particularidades. Na falta de uma garantia de equivalência entre a coisa e o pensamento da coisa, surge o "método", e o conhecimento do mundo se daria, a partir de então, através de leis gerais e universais. Assim, a matemática torna-se a principal forma de demonstração em ciência, por ser universal e axiomática. Surge o "ideal de ciência"; sobre o modelo da Física Clássica, nasce uma ideologia da supressão da subjetividade.

A atividade científica se estabelece como aquela que produz conhecimento do mundo; a ciência, na sua relação com o "real", constrói modelos que falam a 
respeito dos "fenômenos do real". Este discurso é, portanto, um discurso "feito de fora"; sobre o que é a realidade e independente daquele que conhece. É um discurso formal, consistente e não representativo, embora explicativo e realista (CHALMERS, 1982). O resultado desse discurso é um "real científico", uma construção que contém componentes de ambos, do objeto dado e do sujeito, ou seja, um objeto de conhecimento (BACHELARD, 1984). Não é representativo porque não representa um objeto, mas explica um fenômeno, construindo, nesta explicação, objetos de conhecimento capazes de se apropriar do real e nele atuar como técnica (ALTHUSSER, 1985). Contudo, é realista, na medida em que, embora não pretenda descrever/representar este real, assume que os fenômenos independem do observador e de seus construtos a respeito deles, os objetos de conhecimento que constituem um real científico.

\section{UMA CISÃO}

Em fins do século XIX e início do século XX, ocorre, no plano da construção de conhecimentos, uma outra revolução. O bon dieu cartesiano, garantia contra as paixões enganadoras do malin genie sai de cena. Freud, Marx e Nietzsche vêm equivocar a suposta certeza construída na coincidência do "eu" do "eu penso" e do "eu" do "eu sou" (COTTET, 1989; FOUCAULT, 1987). Esbarramos, assim, na possibilidade de um saber estranho ao "eu" - lugar do falar, pensar - e que, no entanto, me constitui - enquanto ser. Gödel, no seu primeiro teorema da incompletude (DETLEFSEN, 1998), demonstra que mesmo um sistema formal axiomático comporta a possibilidade de uma assertiva não passível de demonstração através do próprio sistema e que, portanto, é um estranho, sendo, no entanto, necessário para garantir a consistência do sistema. Ou seja, existe um furo no conhecimento, um impossível de saber, um não-saber, mesmo no seio do próprio paradigma da abstração conceitual, a matemática. $\mathrm{O}$ teorema de Gödel surge em resposta às aspirações de Hilbert e Ackerman de que todas as fórmulas válidas logicamente pudessem ser demonstráveis dentro de um sistema lógico quantificacional de primeira ordem, e que não entrariam em contradição com o sistema. Após demonstrar que tal proposição era verdadeira, tentou expandi-lo para sistemas formais mais abrangentes, de tal modo que incluísse mesmo sistemas capazes de englobar todos os métodos conhecidos de demonstração matemática. No entanto, mesmo sentenças aritméticas simples eludem tal ambição de provar ou refutar qualquer afirmativa derivável de um sistema lógico consistente, ameaçando sua consistência justamente por entrar em contradição com este. ${ }^{1}$ Deste modo, esvai-se a possibilidade de fundar uma certeza sólida concernente à atividade científica, mesmo recorrendo-se aos enunciados necessários e protegidos das contingências e das ilusões da realidade. Portanto, de alguma forma, morre a certeza, morre Deus, o conhecimento construído sobre esta viga mestra ameaça ruir. 


\section{O Lugar da PSiCANÁlise}

A psicanálise será o lugar em que se dá a escuta do choro das viúvas do Deus morto, as histéricas. Aquelas para as quais Gödel depôs em favor. Elas também vêm mostrar com seu pranto, que todo conhecimento é falho, furado, nada é suficiente. Por este motivo, a psicanálise é uma escuta privilegiada deste saber que escapa ao conhecimento racional, que resiste, que denuncia o furo de todo conhecimento. A entrada em questão destas considerações, torna possível, talvez, entender porque o lapso, o chiste e o sonho, são patentes de depor a favor de uma outra ordem de produção de sentidos, completamente estranha ${ }^{2}$ ao eu. Saber o furo de todo conhecimento é de fato se deparar com um impossível de saber, um não-saber. Diante dessa falha re-conhecer "a" ignorância, matematizar o impossível.

Dessa forma, o lugar da psicanálise é aquele de um discurso, de uma experiência, a experiência analítica, que não se faz (a partir de um olhar lançado) "de fora" por que ela está no mesmo campo do fenômeno; mais ainda, a experiência analítica é o próprio fenômeno. Dentro e fora perdem o seu sentido, a posição do analista é a própria posição da verdade. Portanto, o discurso não é sobre nada, é um discurso da experiência de ser não sendo quando se é ao ocupar a posição de ser. Como é um discurso do que é, mesmo sem ser, a psicanálise é apenas um discurso a respeito da experiência de ser, quando não se é. Não é refutável, questão cara às epistemologias de matiz popperiano (POPPER, 1977), porque é. A psicanálise não é dentro ou fora, ela é. Como é, não produz saber, é o saber da verdade que só ela sabe, porque "é". A chave para o entendimento disto que se insiste aqui em dizer é o conceito psicanalítico de "transferência", ou seja, o endereçamento, ao "Outro", da questão que surge do reconhecimento de que existe um saber de si que lhe é estranho, e cujo conhecimento é atribuído ao "Outro". $\mathrm{O}$ analista anda sobre o fio da navalha: ao mesmo tempo que não pode se destituir do saber a ele atribuído, tampouco pode assumi-lo como seu, pois fazê-lo acarretaria como pena obturar a dimensão da "causa" do sofrimento do analisando, tamponando a hiância na qual se encontra instalado o mito com um saber detido $a$ priori. A produção do saber em análise só é possível através da inclusão do analista nesse mito, através do sintoma - ou seja, através da construção dessa dinâmica mítica no endereçamento ao analista. É nessa tentativa de captura do analista por parte do discurso do analisando que se produz o dizer histérico: todo conhecimento é falho, nada é suficiente.

Assim sendo, a grande especificidade do fenômeno analítico, em comparação aos fenômenos estudados nas ciências da natureza, ou de outros mecanismos de produção de conhecimento que as tenham como ideal, é o de se dar com a participação de seu suposto observador - o analista. O setting psicanalítico (composto de sujeito do suposto saber, analisante e grande Outro) e a conseqüente aparição do fenômeno analítico, dependem da colocação em jogo da dimensão inconsciente no analista. Logo, segundo o modelo tradicional de produção de 
conhecimento científico, analista e analisante constituem o fenômeno - não sendo possível, assim, observar qualquer fenômeno, mas sim vivenciá-lo, experienciá-lo.

\section{UM (NÃO) SABER}

Temos então, que o que é produzido na análise é um saber - idiossincrático, e que não nos informa sobre a realidade, mas que possui valor de verdade no mito individual que sustenta o fantasma neurótico. Admitindo a proposição de Jacques Lacan acerca da cisão do sujeito, cisão esta que funda o sujeito do Inconsciente, faz-se necessário que admitamos também uma conseqüência desta cisão - a falta, constitutiva do sujeito e que é pano de fundo para o célebre dito de Lacan: "Penso onde não sou, sou onde não penso" (LACAN, 1964/1995). No entanto, esta falta não se encontra a descoberto no sujeito; será recoberta pelo "fantasma", construção realizada pelo sujeito para dar conta de uma pergunta para a qual ele não tem resposta - e para a qual, é importante frisar, não existe uma resposta correta. Mais ainda é preciso que se diga: nem errada. A resposta construída pelo sujeito para dar conta desta pergunta que insiste, pela qual é constantemente interrogado, não possui uma contrapartida na realidade objetiva, ou seja, não pode ser contestada pela realidade dos fatos. Isto decorre desta resposta não ser construída a partir de condições sócio-ambientais supostamente determinantes da personalidade, comportamento ou qualquer outra classe psicológica que se possa aqui discriminar mas, sim, advém do posicionamento do sujeito diante dessa falta constitutiva, desse desejo impossível de saciar.

Dito isto, é possível agora, talvez, entender por que as formações do Inconsciente - o lapso, o sonho, o sintoma - são os efeitos de verdade do Incons-ciente: pois, se a linguagem é incapaz de encerrar em si mesma o sentido pleno do dito, sendo necessário que o Outro atribua sentido ao discurso enunciado pelo sujeito, abre-se aí a possibilidade que o enunciado fale mais do que objetiva a consciência, ou seja, que a linguagem se constitua como um carreador das formações do Inconsciente. Assim, o sujeito cartesiano, "que não é senhor em sua própria casa", cede espaço ao sujeito $(8)$ que, barrado pela linguagem e pelo desejo, mostra-se, de forma caprichosa, no ato falho, no estranhamento do dito, no relato de sonho. Mostra-se dividido, falha na estrutura.

Isso ocorre porque as unidades de composição do discurso, os signos, não possuem correspondência unívoca e inequívoca com objetos da realidade, não podendo ser decompostos em significante e significado que se implicam mutuamente dentro de uma membrana envoltória. Logo, um significante é completamente desprovido de sentido, a menos que esteja em relação com outros significantes e, além disso, que seja dirigido a um outro. O pensar, por sua vez, constitui o efeito de verdade da ciência, uma vez que o pensamento, a formalização abstrata, como vimos anteriormente, estão salvaguardados das contingências do mundo sensível. O saber inconsciente precede o sujeito (o constitui sujeito), enquanto o inverso é o sujeito cartesiano, o sujeito da ciência (a constitui ciência). Isso não significa que o sujeito do inconsciente seja ausente; ele falta, é certo, mas fala, é o sujeito da 
enunciação. É por isso que entre o sujeito e o significante não existe uma relação dada, é preciso construir a sutura que nomeia "a relação do sujeito à cadeia de seu discurso" (LACAN,1964/1995), e que, portanto, faz mediação entre o impossível do sujeito e o impossível da linguagem.

Portanto, somos uma falta na estrutura, tanto do ponto de vista da linguagem (somos um S barrado, registro do simbólico), quanto do ponto de vista do desejo ("a" falta, objeto a, registro do imaginário alçado pelo simbólico). Mas quem é esse novo registro, o imaginário? Somos nós constituídos moi, na identificação cheia de alteridade com a nossa imagem no espelho, identidade esta cuja garantia se funda não em nós mesmos, mas no olhar do outro. Neste espelho, o mesmo e o outro, o júbilo narcísico e a perda testemunhada pelo "outro" olhar, espelho plano, alça simbólica.

\section{Produção de Conhecimento em PSicanálise}

A psicanálise é conhecimento de um fenômeno que não pode ser verificado. Uma das grandes teorias da ciência moderna padece de problema semelhante: a teoria evolutiva. Esta teoria trata de fenômenos que ocorreram no passado e, como tais, não são passíveis de observação direta, logo, também não podem ser verificados. Contudo, uma série de evidências indiretas do passado, como os fósseis, nos informam que o processo evolutivo tem alterado o conjunto de seres vivos que habitam a Terra. Do mesmo modo, experimentos de laboratório demonstram a capacidade das forças evolutivas de alterar a constituição genotípica e fenotípica das populações naturais no presente (SILVA, 2001).

No caso do conhecimento analítico o problema é maior. Diferentemente da teoria evolutiva, o fenômeno analítico não se dá no passado, mas no presente. Contudo, não é passível de observação direta porque existe como experiência vivida, o suposto observador é parte do fenômeno, logo, não existe um olhar de fora. A objetividade garantida pela distinção entre sujeito e objeto se esvai. Se o presente na psicanálise é como o passado na teoria evolutiva, resta ainda o seguinte problema: como operar a reconstituição desse dado, passado na teoria evolutiva, vivido no setting, um "vividado"?

A questão que se coloca então é: qual a possibilidade de produção de conhecimento numa experiência com as singularidades descritas acima? Ou seja, conhecimento do que não existe como objeto, enquanto se dá o fenômeno, e uma vez findo, o fenômeno, não existe como dado. Assim sendo, embora a psicanálise padeça dos mesmos problemas da teoria evolutiva, não conta com as suas soluções. Em psicanálise não há a possibilidade de se construir um dado concreto a partir do resgate de indícios materiais ou experimentos controlados, porque os indícios são eles mesmos construídos. Sendo o sujeito, pontual e evanescente, efeito da linguagem, o sentido não é dado, não está posto e fechado, desliza na cadeia significante, sendo produto de um ponto de basta que o traz para o presente. $\mathrm{O}$ indício é uma nomeação, ele próprio uma interpretação. ${ }^{3}$ 
Para que a produção de um conhecimento sobre o setting analítico possa se operar, faz-se necessário, nesse momento, constituir uma primeira diferenciação. O conhecimento, aqui posto em questão, diz respeito, especificamente, ao que neste setting ocorre, em detrimento da produção de um conhecimento a partir dele. Tal diferenciação também parece ser explicitada pelos dizeres de Hilton Japiassu ${ }^{4}$ sobre a singularidade do conhecimento analítico. Tal conhecimento, segundo ele, não pretende, a princípio, falar de um outro tipo de relação que não aquela que é estabelecida entre aquele que, em sofrimento, supõe na figura do analista um Outro, suposto saber o que lhe aflige, e o analista, em sua ética, que se furta a esta posição, permitindo, assim, a emergência, nessa relação, de um novo sujeito, o sujeito do Inconsciente. Este sujeito é aqui, pois, efeito, neste setting, de uma articulação significante endereçada e colorida do afeto transferencial ao analista.

É em congruência com esta lógica que aqui se afirmará que, para a construção desse conhecimento, deve-se fazer operar uma disjunção temporal entre o pretenso sujeito epistêmico, aquele que elabora o conhecimento, e o aqui suposto objeto de seu conhecimento, o setting analítico, no qual ele está implicado. Este dispositivo diz respeito à emergência, anteriormente mencionada, do sujeito do Inconsciente, diverso do epistêmico. Tal construção apenas se faz possível com a intervenção no tempo, ou seja, é preciso que haja uma disjunção temporal entre este sujeito epistêmico e o seu objeto de conhecimento. É preciso que o conhecimento elaborado pelo sujeito epistêmico se dê no futuro em relação ao presente da experiência analítica. Neste futuro, contudo, o que se opera não é a rememoração de uma lembrança, visto que o sujeito epistêmico compõe também seu objeto, é um futuro lógico, capaz de, sobre o presente, tomado aqui como o momento no qual ocorre o fenômeno analítico, construir uma escuta desse discurso em transferência.

Esta disjunção ocorreria através da interposição de um passado (condição de produção do conhecimento), entre o presente do setting ("vividado"), o momento da verbalização do discurso, e o futuro, o a posteriori, no qual o sujeito deve elaborar o conhecimento. Essa operação, de forma alguma é avessa à lógica do setting, em verdade é demandada por este e mostra-se pertinente àquilo que é produzido no endereçamento de significantes ao analista. A (re)construção da dimensão imaginária do mito neurótico também se opera segundo esta lógica presente-passado-futuro (PELBART, 2003). A predominância do "nada quero saber disso" do recalque cede, sob elaboração, àquilo que Freud em "Recordar, Repetir, Elaborar" chama de considerar a dimensão inconsciente como um "inimigo digno de sua têmpera" (FREUD, 1914/1990). O sujeito emerge, portanto, nesse pôr-anomear o passado que nunca se realizou. É posto então que esta disjunção temporal não se dá no tempo da física, homogêneo e extrínseco ao fenômeno, mas no tempo da escuta, e é tão repleto de singularidade quanto o sujeito que emerge da relação analítica. Nessa "nova" seta de tempo, o passado está entre o presente e o futuro, e é a condição de possibilidade de um conhecimento analítico. 

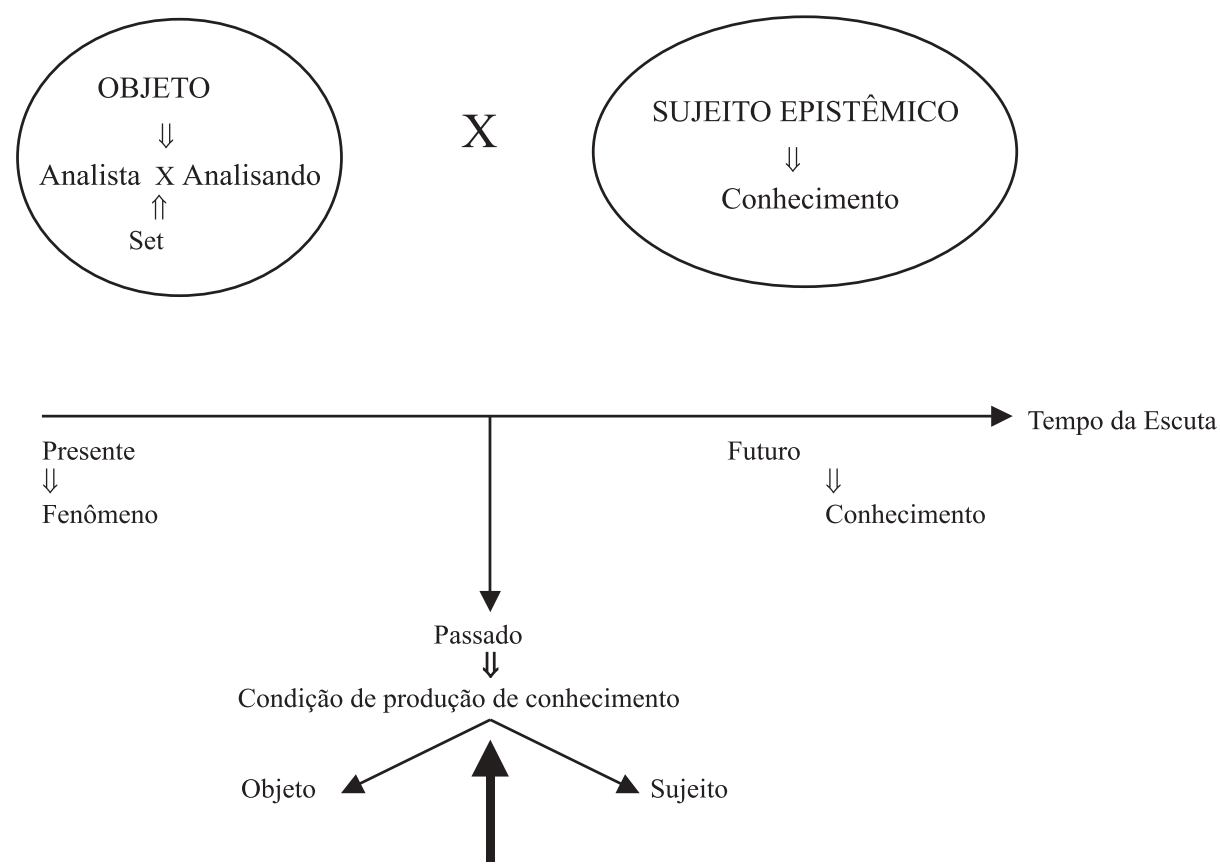

Disjuntos no tempo da escuta

Figura - A interposição do passado tornando disjuntos o presente do setting e o futuro no qual o sujeito deve elaborar o conhecimento. Essa operação de disjunção temporal não se dá no tempo da física, mas no tempo da escuta e é a condição de possibilidade de produção de um conhecimento analítico.

\section{Conclusão}

Por um lado, pudemos ver que a epistemologia pode informar a psicanálise, no sentido de nomear determinadas condições da produção de conhecimento no setting - Lacan, no seu Seminário RSI, já aponta a necessidade de o analista ser dois. Por outro lado, observamos como a introdução da idéia de um furo no conhecimento, análogo a um furo na verdade, nos convoca a recobrir esse furo com uma interpretação, tal como o neurótico o faz na construção de seu mito. Desse modo, nem mesmo a referência em algo fora do sensível, como a lógica ou a matemática, 
e, portanto, não suscetível às suas contingências, pode ser tomada como garantia de consistência, pois mesmo aí não há esta possibilidade.

Assim sendo, cumpre-nos, nesta dupla visada, pensar as possibilidades de construção de uma epistemologia que contemple a incompletude, que não se esquive quanto às exigências do não-objetivável. Ou seja, repensar o sujeito cognoscente a partir do corte que Foucault chama de advento da hermenêutica moderna. Além disso, cumpre notarmos que, se a matematização é uma maneira de recobrir as exigências da produção de conhecimento, esta mesma é derivada de outras exigências e idéias. ${ }^{5}$ Logo, é preciso que analisemos ao que este recobrimento responde, sem que, com isso, queiramos psicanalisar a obra de Galileu, Descartes ou Popper. No entanto, esta é uma maneira de estabelecer um campo para outras formas de produção de conhecimento, e mesmo de pôr em debate a especificidade e validade do conhecimento produzido cientificamente.

\section{Notas}

1 Eis uma rápida demonstração do teorema de Gödel: "Let a given system T satisfy the following conditions: (1) it is powerful enough to prove of each sentence in its language that if it proves it, then it proves that it proves it, and (2) it is capable of proving of a certain sentence G (Gödel's selfreferential sentence) that it is equivalent to ' $G$ is not provable in $T$ '. Under these conditions, $T$ cannot prove $G$, so long as $T$ is consistent. For suppose $T$ proved $G$. By (1) it would also prove ' $G$ is provable in T', and by (2) it would prove ' $G$ is not provable in $T$ '. Hence, T would be inconsistent."

2 A palavra "estranha" aqui figura com o sentido usual do termo estranho (Unheimlich) em psicanálise.

3 Cf. Foucault, 1987, para uma discussão do papel da interpretação nas obras de Nietzsche, Freud e Marx.

4 Quanto a esta especificidade afirma Japiassu (1989, p. 60): "E sua intersubjetividade é de outra ordem: trata-se da relação dual da análise, não da relação universal e pública. Embora presente nas preocupações da psicanálise, a intersubjetividade universal só surge a posteriori, naquilo que pode ser elaborado e publicado a partir da intersubjetividade inicialmente particular e dual da relação analítica."

5 Galileu, por exemplo, é considerado o criador da ciência moderna por romper com a tradição aristotélica, uma vez que despoja o objeto de suas características sensíveis (qualidades) - rápido, pesado, alto, baixo - propondo a matematização do empírico como um todo, no que tem de passageiro, ao contrário da episteme antiga que propunha a matematização apenas do que fosse eterno e necessário.

\section{REFERÊNCIAS}

ALTHUSSER, L. Freud e Lacan, Marx e Freud. 2. ed. Rio de Janeiro: Graal, 1985.

BACHELARD, G. Filosofia do não: filosofia do novo espírito científico. 3. ed. Lisboa: Presença, 1984.

CHALMERS, A. F. What is this thing called science? 2nd ed. London: Open University Press, Milton Keynes, 1982.

COTTET, S. Penso onde não sou, sou onde não penso. In: Miller, G. (Org.) Lacan. Rio de Janeiro: J. Zahar, 1989. 
DESCARTES, R. Meditações. São Paulo: Nova Cultural, 1641/2000. (Os Pensadores).

DETLEFSEN, M. Gödel's theorem. In: CraIG, E. (Org.). Routledge Encyclopedia of Philosophy. New York: Routledge, 1998.

FOUCAULT, M. Nietzsche, Freud \& Marx: Theatrum Philosoficum. 4. ed. São Paulo: Parma, 1987.

FREUD, S. Recordar, Repetir e Elaborar. In: . Edição Standard Brasileira das Obras Psicológicas Completas de Sigmund Freud. Rio de Janeiro: Imago, 1914/1990. v. XII.

JAPIASSU, H. Psicanálise: Ciência ou Contraciência? Rio de Janeiro: Imago, 1989.

LACAN, J. Seminário. Livro 11: Os Quatro Conceitos Fundamentais da Psicanálise. 2. ed. Rio de Janeiro: J. Zahar, 1964/1995.

PELBART, P. Tempo e Psicanálise. In: . A Vertigem por um Fio: Políticas da Subjetividade Contemporânea. São Paulo: Iluminuras, 2003.

POPPER, K. Autobiografia Intelectual. São Paulo: Cultrix/EDUSP, 1977.

SILVA, E. P. A short history of evolutionary theory. História, Ciências, SaúdeManguinhos, Rio de Janeiro, v. 8, n. 3, p. 671-687, set. 2001.

Recebido em: julho 2004 Aceito em: agosto 2005 